\title{
461\%
}

\section{The selfie generation: a transformation of visual social relationships}

\section{Fiona Andreallo}

\section{Resumo:}

A geração selfie é um termo comumente usado para descrever pessoas nascidas depois de 1981 devido à suposta proliferação de selfies que elas fazem diariamente. Se as selfies realmente definem uma geração de pessoas, elas requerem consideração enquanto uma evolução da interação social. Este estudo interdisciplinar centra-se na fotografia como desempenho de olhar envolvendo as relações sociais entre as pessoas. Pergunto: como podem as selfies sugerir uma transformação das relações sociais quotidianas? A selfie como performance fotográfica ativa é examinada pela observação etnográfica ilustrativa. Então, como objeto fotográfico performático, a selfie é examinada como comunicação visual interativa (Kress \& Van Leeuwen, 2006; 2009). Finalmente, os espaços performativos da selfie em processo (da performance inicial, ao objeto e como é partilhado e se move entre espaços privados e públicos) são examinados como relações de perceção proxémica (Hall, 1966). Para a geração selfie, os espaços privados nas relações sociais talvez tenham evoluído não apenas por causa de mudanças na tecnologia fotográfica, mas também por novos espaços de socialização, nos quais os contextos público e privado são muitas vezes indistintos e não fixados

Palavras-chave: visual; espaço; performance; proximidade; intimidade, fotografia, comunicação visual, tecnologia móvel.

\section{Abstract:}

The selfie generation is a term commonly used to describe people born after 1981 because of the supposed proliferation of selfies they take daily. If Selfies indeed define a generation of people, then they require close consideration as an evolution of social interaction. This interdisciplinary 
study focuses on photography as performance of looking involving social relationships between people. I ask "How might selfies suggest a transformation of everyday social relationships?" The selfie as active photographic performance is first examined through illustrative ethnographic observation. Then as performative photographic object the selfie is examined as interactive (Kress \& Van Leeuwen's, 2006, 2009) visual communication. Finally, the performative spaces of the selfie in process (from initial performance, to object and as it is shared and moves between private and public spaces) is examined as relationships of proxemic perception (Hall, 1966). For the selfie generation the private spaces in social relationships has perhaps evolved not simply because of changes in photographic technology, but also new spaces of socialising where private and public contexts are often blurred and unfixed.

Keywords: visual; space; performance; proximity; intimacy, photography, visual communication, mobile technology.

\section{Introduction}

What might the performative spaces of selfies suggest about a transformation of visual social relationships for the selfie generation and indeed all those who practice and share selfies? Selfies are highly influential, so much so that the practice is often used to identify a generation, suggesting that it has changed the ways we traditionally think about visual communication. The ease in which a selfie is produced and shared means that there are more self-representations produced than ever before in history. Such forms of visual culture are already a popular choice of everyday communication and the ubiquity of everyday use urges further investigation (Leaver \& Highfield, 2016).

Visual relationships are an active process or performance that are spatially located. Visual culture studies conceptualize the visual beyond universal textual devices (Mitchell, 1994: 16) and considers looking as spatially organized (Alpers et al. 1996: 26). 'Visual experience' or 'visual literacy' is not fully explicable in a model of textuality (Mitchell,1994: 16) because visual experience involves many senses and is not solely dependent on sight (Mitchell, 2013: 7-14). Performance is understood in this study as an interaction between people as well as between people and technology that is explicitly linked to spectacle and public space (Williamson et al., 2014). I approach the question through ethnographic examination of selfie performance and spatiality, understanding visual social relationships as interactive (Kress \& Van Leeuwen, 2009) and involving gestures of proxemic perception (Hall, 1966).

My argument is as follows. Although the term selfie generation aims to define a generation, it also locates a transformation of visual social interaction. As a derogatory 
term, selfie generation aims to define a generation as selfish or self-obsessed. However, closer examination of the performative spaces of selfie practice suggest a shift in how concepts of private space and intimacy are visually understood and communicated.

In what follows, I consider selfies primarily as visual spaces of social relationships. First, I examine ethnographic performance illustrations to consider initial spaces of a selfie performance in comparison to a traditional camera performance. The physical spaces in the initial selfie performance are identified as closer in proximity thus suggesting a shift towards the performance as more intimate. In the second section I concentrate on the selfie as a photographic image. I locate Kress and Van Leeuwen's (2006) considerations of how visual images actively communicate through signifying elements of gaze, angle and distance in the case of selfies. Selfies are identified as communicating intimacy and private space in most cases. The observations also suggest an evolution of how such elements of the image are understood. The final section draws on Halls (1966) theory of proxemic perception to understand performative spaces (as are they represented in the image and performance of image making and sharing) as social communicative interactions.

\section{Selfies as Visual social relationships (literature and methodology)}

Despite the acknowledgement that visual communication in social media involves gestures of body and movement (Baym \& Senft, 2015; Frosh, 2015) as social interaction, there is yet a study to examine digital visual communication as performance. Focusing on selfies as photography Frosh (2015) has proposed that selfies communicate beyond the visual to also include movement and bodily interaction he describes as kinesthetic sociability. Centering also on movement and gesture Baym and Senft (2015) suggest that visual practices such as selfies involve movement of agency that might be described as a grab.

Performance and performativity highlight an interest in everyday process and active engagement that is particularly useful in understanding photography. Extending from my background as a digital media artist I understand photography as both a performance in which images are constructed, and as performativity involving a process and active engagement with people through technology. The term performativity in performance studies was differentiated in the 1990's to highlight the idea of process and active engagement (Fisher-Lichte, 2008a, 2008b) and move away from dominant semiotic readings of performance that dissects props, gestures and lighting of a performance. Essentially the concept of performativity differentiates itself from performance that might be associated with traditional concepts of theatre, or indeed traditional forms of analysis. In human computer interaction and design studies, performativity has served to 
understand the interaction as active process between computers and humans (Ehn et al., 2007).

Performativity focuses on ideas of process and active engagement essential to understanding vernacular creativities (Burgess, 2007). The idea of process includes considering an event rather than a single object or result. Acknowledging active engagement distinguishes from passive perception or experience. Therefore, the idea of photography as process acknowledges the active performance and agency of participants in the creation of a photograph as much as the image itself. In everyday digital contexts the term vernacular creativity (Burgess, 2007) has been used to describe publicly active participation in everyday practices such as digital memes or selfies. The participation of sharing and creating selfies and digital memes is as important as the image itself in the social interaction.

Performance essentially involves movement, bodies, ideas of space and how these work within social relationships of power. Ideas of space are central to ideas of looking and visibility. A photograph can make an object, person or idea visible. To make oneself publicly visible, or an idea publicly visible is a form of power (Frosh, 2001). Ways of being that are not represented in public spaces are treated as invisible. This is why it is important to provide facilities for all people to have access to public spaces. Indeed, it is a pivotal reason why people fight for disability access to public events, or toilets that are not exclusive to gender. Another example of a relationship of power through the gaze is one of control explained by Foucault (1979) through the illustration of Bertram's panopticon. The panopticon was a plan for a prison where a guard sat in a central tower with the prisoner's cells arranged in circular form around the tower. The prisoners could not see the guard, and in fact the guard may not even be in the tower, but the idea they were being watched sought to control the prisoner's actions. The gaze that controlled the prisoners in the panopticon is also the gaze that works to control people's actions through surveillance cameras. In online contexts Mann (2004; Monahan, 2006) has used the term sousveillance to describe the ways the visual surveillance relationship has transformed. Home videos of police violence is one form of sousveillance because it publicly exhibits a gaze from the people that authority seeks to control. Another example is \#wejustneedtopee selfies that trans folk posted of themselves in birth assigned gendered toilets to expose the absurdity of conservative politicians that aimed to pass laws limiting people to toilets of their birth gender. The power relationships of looking are suggested by the word sousveillance itself because 'sous' means from below and suggests that people once treated as passive now publicly and actively look back. In the spaces of the photographic object itself, visual interaction has been acknowledged as active through gestures of the gaze. The depicted person in a photograph looking 
straight at the viewer is described by Kress and van Leeuwen (2006) as performing a look of demand that actively engages with the viewer. When the depicted looks away in the photograph it is a look of offer (Kress \& Van Leeuwen, 2006) where the depicted offers themselves for viewing. The distance to the camera, cropping and angle also place the depicted in a certain position to the viewer of an image and a social relationship. For example, if the camera is angled down at the depicted then this suggest the depicted is submissive or at a lower level in a social relationship to the viewer.

The ideas of offer and demand (Kress \& Van Leeuwen, 2006) as well as proximity (Hall, 1966) are active visual social gestures depicted in the spaces of the photograph. However, limiting the considerations to the depicted and viewer of the image neglects to consider the photographer and agency in this visual conversation. Furthermore, concentrating on the photographic object alone suggests this is the only aspect of the looking performance, when it is in fact just one part of the performance. Everyday digital visual practices through social media such as selfies and digital memes are not only active, but interactive (Andreallo, 2017) and require consideration including, but also beyond the photographic image as visual social interactions. This has become more obvious in digital social media where the immediacy of sharing and ease of image creation is an element of everyday communication.

Hall's (1966) study of social relationships as proximity is useful in complementing the work of Kress and Van Leeuwen (2006) because it provides a means through which distance and space can be considered as unfixed. Proximity (Hall, 1966) considers social relationships between actors based on gestures of proximity that are reliant on the social spaces in which they take place. Essentially Hall (1966) suggests four categories of social spaces that define social distance form the most intimate (intimate space), the least intimate and most distanced proximity between people (public space). Between these spaces are personal and social spaces. Intimate proximity is of course not limited to intimate space and people may appear in intimate proximity in public space, but in the context of the spaces, the proximity gestures differently between people and may cross social taboos from the perspective of the observer. The gestures of proximity are not limited to distance, but they also involve multiple sensory factors including (but not limited to) vision, sound and kinesthesis. If we consider the photograph as a document of the event of a looking performance including proximity, then the image itself gestures a variety of sensory relationships beyond sight. This is because proximity understands gestures generate different meanings in different social spaces. Furthermore, proximity is also useful in considering visual media in movement in social media contexts, as the selfie might be shared, as well as the primary point of the production of the image. 
An ethnographic approach is taken in the consideration of performance as processes of proxemic relationship throughout this study. Ethnography essentially aims towards gaining insight from the point of participant. In this study I understand ethnography as 'a mindset or epistemological approach rather than a specific set of interpretative procedures' (Markham, 2009: 149). In a study considering social relationships of looking, the participant includes the performer as well as the perspectives of the views in that relationship. In this study the focus is on the meanings made through selfie performance as interpreted in social spaces. First the spaces of production of the selfie are considered and explained with illustrative diagrams. Then the social spaces of the performance are considered within the selfie image. Theories of proximity (Hall, 1966) provide a means through which visual relationships of selfies might be understood in movement. It is this movement that is culturally located by people who practice selfies but might be misinterpreted by generations who do not engage with this visual cultural practice.

\section{The performative spaces of selfie production}

Selfies are produced in the most intimate space of the camera (figure 1). A traditional photograph (figure 2) includes a photographer, who looks through a camera device at the object to be photographed. The selfie is most often taken in the mirrored screen of a smart phone where the physical space between the camera and the photographer is limited to the arm or similar close space. Zappavigna (2016) has suggested that the presence of the arm in many selfies draws attention to the intimacy of space, where the photographer physically connects with and reaches out to the viewer with their arm. However, the proximity of the camera to the body of the producer is at once more intimate then earlier photographic practice. The camera is not only within the most intimate and personal social space of the performer but connected to the performer both through the arm and the reflected scene.

The technology of the mobile phone camera, that is notably smaller and inclusive of a reflective screen, is one of the aspects that encourages the intimacy of the performance. The camera is less intrusive in a mobile camera, and the mobility and connection to the devices because of their mobility act as a type of extension of the body rather than a separate mechanical device. The physical space between the photographer and the depicted is also more intimate than in traditional photographic procedures because of the mirrored screen and the size of the camera. 


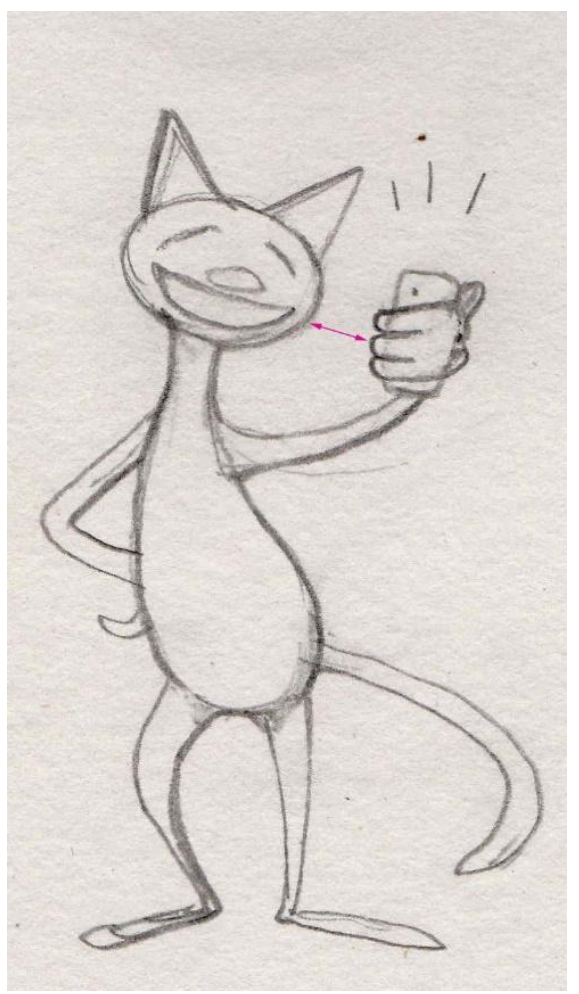

Figure 1. An illustration of a cat taking a selfie. The pink arrow indicates the intimate space between the technology and body of the performer. Image and table the produced and owned by the author

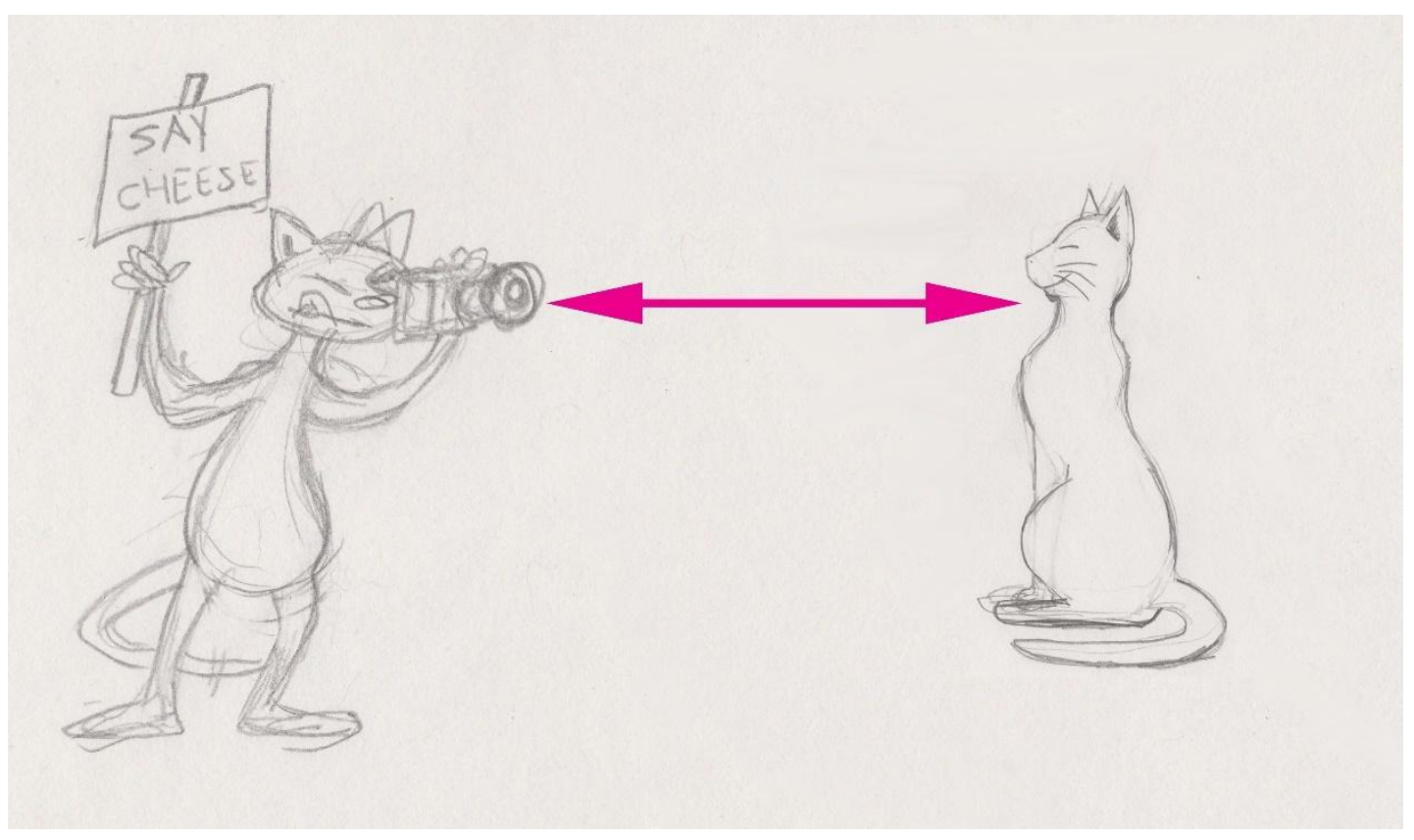

Figure 2. An illustration of traditional photographic spaces between photographer and depicted. The pink arrow indicates a larger and more distanced space tha in figure 1. Image and table the produced and owned by the author

In figure 1, the arrow indicates the intimate space of the photographic performance. The arrow in the space is two-way because there is active relationship between the depicted 
image and the producer as well as the producer and other viewers once the image is shared.

As figure 2 shows, the space between the photographer and sitter is a greater distance than between the mobile camera and producer. Furthermore, the space is interrupted and re-negotiated by the camera. In the case of a selfie, the most typical performance involves a mirrored screen of the camera device and the producer who is also the object of photography (figure 1). The performative space is not interrupted by the photographic device because there is only one space between the producer (who is also the depicted person) and device. When selfies are shot in mirrors rather than screens, the intimacy of the space the producer performs in is explicitly represented. Nonetheless, the space in which a selfie is performed remains the most intimate of photographic social relations, regardless of whether it is depicted or not.

In the initial performance of the selfie greater agency is attributed to the depicted because the viewer is the producer and depicted at once. The selfie producer shares a private mirrored reflection of themselves. This agency of gaze is something unique to selfies. The depicted female body in modern art has been noted as the subject of gaze and is rarely presented as actively looking (Pollock, 1988). The female body gazing into a mirror is represented in traditional art practice as a private moment, where the viewer becomes a voyeur of the private bedroom or space. Such visual representations of space have presented evidence of how certain bodies are perceived and treated in historical contexts, and how the gaze acts a form of power and control.

\section{Selfie as image}

The performative space of selfies is probably most obviously or at least primarily observed in the object or photograph itself. Three main aspects of the social interaction involved in a photographic image discussed by Kress and Van Leeuwen (Van Leeuwen, 2008) include the gaze, angle and distance of the shot.

\section{The gaze}

Selfie producers may choose to depict themselves looking directly at the camera and engaging with the viewer or they may depict themselves looking away from the camera. Capturing a look directly at the camera suggests to the viewer of the image that the depicted person is looking directly at them. The selfie producer is then directly engaging with the viewer of the selfie through the image. When the depicted person in an image looks directly at the viewer it is described as a gaze of 'demand' (Van Leeuwen, 2008: 141 ), because the gaze demands engagement. When the depicted person in the selfie 
does not look directly at the viewer of the image it is described as an 'offer', because the depicted offers themselves up for viewing and does not directly engage with the viewer. However, one could argue that in the case of selfies unlike previous forms of photography, a type of engagement with the viewer is present in both offer and demand gaze simply because of the agency the producer maintains in the production and immediate sharing of their own image.

Theorists such as Foucault (1979), Mulvey (1981, 1989), Haggerty (2006) and Metz (1974) have considered the idea of the gaze for how it exercises power in society. As previously mentioned, Foucault's (1979) exploration of the gaze as a form of control. The panopticon and security cameras (dummies or working cameras) are examples of the way a gaze, or even a perceived gaze provides a way of controlling people's actions. The gaze in such situations works as a power that is attributed to the viewer (or perceived viewer). In such social situations the viewed is subject to the viewer with less power because their gaze is not recognized and does not exercise power or control in the social relationship. Mulvey $(1981,1989)$ examined film noir and how the gaze limited ways of being for female bodies. Haggerty (2006) and Mann (2004) have considered relationships of looking and power constructs in online environments suggesting an evolution of the panopticon to consider the gaze as a power that is contested. As photography is essentially a practice of looking it is important to examine any photographic practice including selfies for how this power relationship plays out.

As I mentioned previously, the gaze of the selfie producer gains agency of looking that was not often the case with earlier photographic technology. First the mirrored screen provides a means through which the photographer is at once producer and chooses how they are to be seen. The gaze in the represented image is mainly attributed to what might be described as a gaze of 'offer' or demand' (Kress \& Van Leeuwen, 2006).

If the selfie producer chooses to perform a demand gaze, they interact directly with the viewer demanding response. A demand gaze actively engages and because of this it might be considered a more powerful gaze. Furthermore, in the case of selfies this gaze is more direct because it is not mediated through another photographer (or gaze) but directly to the viewer from the subject.

If the gaze of offer is chosen, then the selfie producer has chosen to offer themselves up for gaze. The depicted person has actively represented themselves in this way. Unlike traditional photographic practice involving separate photographer where offer suggests a more subjective view of the depicted gestured as caught unbeknown to the viewer, the selfie actively offers.

The agency of viewing in the selfie mirrored screen has evolved because it gains greater agency for the producer then traditionally awarded. However, once the image is shared 
then the agency of the image, and the context of its sharing or viewing is out of the control of the producer. Once it is shared perhaps the producer has less agency then traditionally awarded simply because of the reproducibility and speed of transmission in sharing.

\section{The angle}

The angle of the camera to the sitter produces different meanings in power relationships between the depicted and viewer. The camera lens angled from above the depicted signifies the depicted as less powerful or perhaps submissive to the viewer. The camera lens from a great angle below suggests the depicted is powerful and often power figures are depicted with this angle. When the lens is level between the viewer and depicted the social relationship is gestured as on equal footing. These angles of viewing also signify in everyday social relationships, for example if someone stands or sits at a higher level to another their view and power relationship is dominant.

An extreme $45^{\circ}$ angle above the depicted is a common trait in many selfies, and this might suggest that such selfies are submissive. However, the angle does not work alone to make meaning. When considering a selfie, or any image, it is any of the signifying elements in relation to each other and in the contexts that they are presented that gesture meaning. The $45^{\circ}$ angle in the contexts of selfies is most often useful to include enough background in the image because the distance of the technology is limited by the distance of the arm or stick. Furthermore, the angle from above in a close up of the face is complimentary because it narrows the chin and make eyes appear bigger with foreshortening. Uglies or ugly selfies most often adopt a $45^{\circ}$ angle from below the chin further highlighting the concept the angle plays in complementary representations. Most importantly the selfie is produced on a particular angle by the choice of the producer and this grants more agency to the depiction because the depicted is actively involved in the production. The meaning then includes a knowledge of the performance, and the intent of the producer. The meaning gestured that is purely visual must include the context of all the elements of the image, the key four being gaze, angle, distance and facial expression.

\section{The close-up and distance}

Selfies are inherently photographed in closeup because they are mostly limited by the distance of the arm or selfie-stick of the producer. The photographic close-up suggests intimacy, and the greater the distance of the figure in the frame, the less intimate is the gesture of the social relationship between the depicted and viewer (Kress \& Van Leeuwen, 2006). Selfies, then, inherently gesture intimacy and this intimacy has been 
discussed as great length by academics described as 'a hug' (Warfield, 2015) and recognized as intimate connection (Zappavigna, 2016). This intimacy is indeed enhanced by the immediacy of the sharing of the images, and this will be discussed further through the concept of proximity.

However just as the angle or gaze must be contextualized to understand the gesture of the meaning, the close-up in the context of selfies can indeed gesture more than intimacy and indeed different levels of intimacy. The close-up can signify dominance or threat, just as standing too close to someone in an everyday social relationship might threaten or cause discomfort. Selfies have been criticized as immoral and sexualized, but perhaps the selfie is not being understood in the cultural or visual signifying context that it signifies. Those unfamiliar with the practice (perhaps from other generations) might misunderstand or paint all selfies with a broad stroke as 'too intimate'. In the following section I will consider how we gesture through proximity and locate this in traditional photographic practice to the selfie.

\section{Selfies; proxemic social relationships as image and performance}

The selfie is a relationship between the viewer and the depicted, and in everyday social relationships people gesture (to each other and those around them) familiarity and intimacy through proximity. Hall (1966) studied American intellectuals to understand relationships of proximity in social settings. Hall defined four spaces of social proximity; intimate, personal, social and public. He observed these social proximities between people as limited to specific social spaces to avoid taboo. When Kress and Van Leeuwen write about social interaction through photography, they describe the types of shots indicate the proximity that is gestured to the viewer. These shot types are terms commonly known and employed by professional photographers. Kress and Van Leeuwen (1996) suggest that close shots such as extreme close shots (ECU) and closeups (CU) express greater intimacy between the viewer and subject. Furthermore, long shots (LS,) where the depicted is smaller in the frame, expresses more disassociation and less intimacy between the viewer and the depicted. 
Table 1 A visual representation of Hall's (1966) description of social relations gestured through proximity

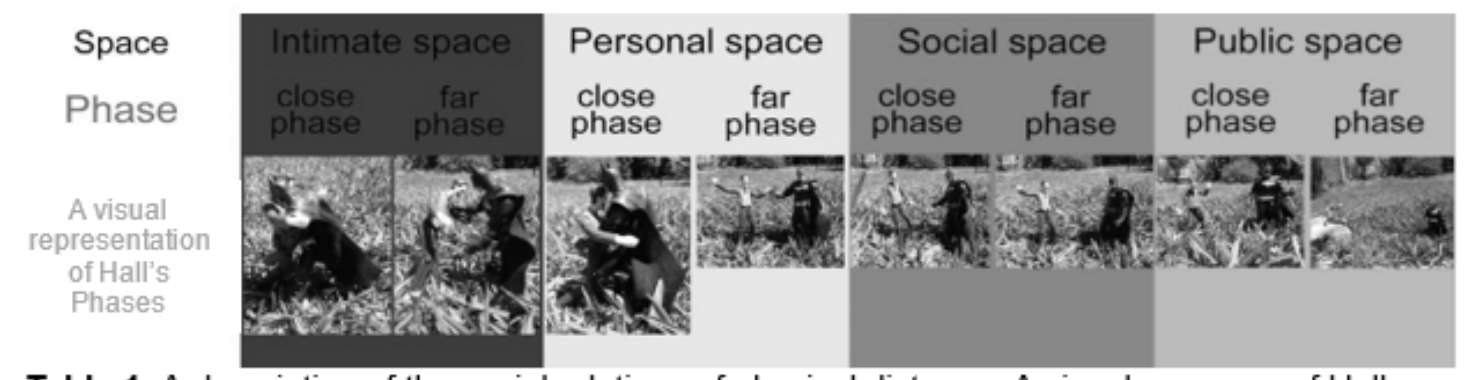

Table 1. A description of the social relations of physical distance. A visual summary of Halls proxemics in social relationships. Image and table the produced and owned by the author

To visualise proximity as Halls observations between people in the relationships of the viewer and the depicted in selfies, I created a visual table of batman selfies. The figures chosen for this exercise do not have meaning, rather they were models to define visually ideas of space or proximity in social relationships. A visual representation of Halls five spaces might look like the images in table 1. Note that each of the four spaces are split into two phases. These phases within the spaces often overlap without any clear boundary. The intimate space includes two phases of the most intimate and familiar gestures. In these two phases the bodies touch. The personal space in the far phase and the social space in the close phase can include touch but at a distance, however here hands may touch. The public space is the most distance spaces where I have defined the figures in the distance and distant from each other. Table 1 serves as a visual description and summary of the spaces and phases. 
Table 2 Comparison table of social distance as proximity (Hall, 1966) \& shot types (Kress and Van leeuwen, 1996) of selfies

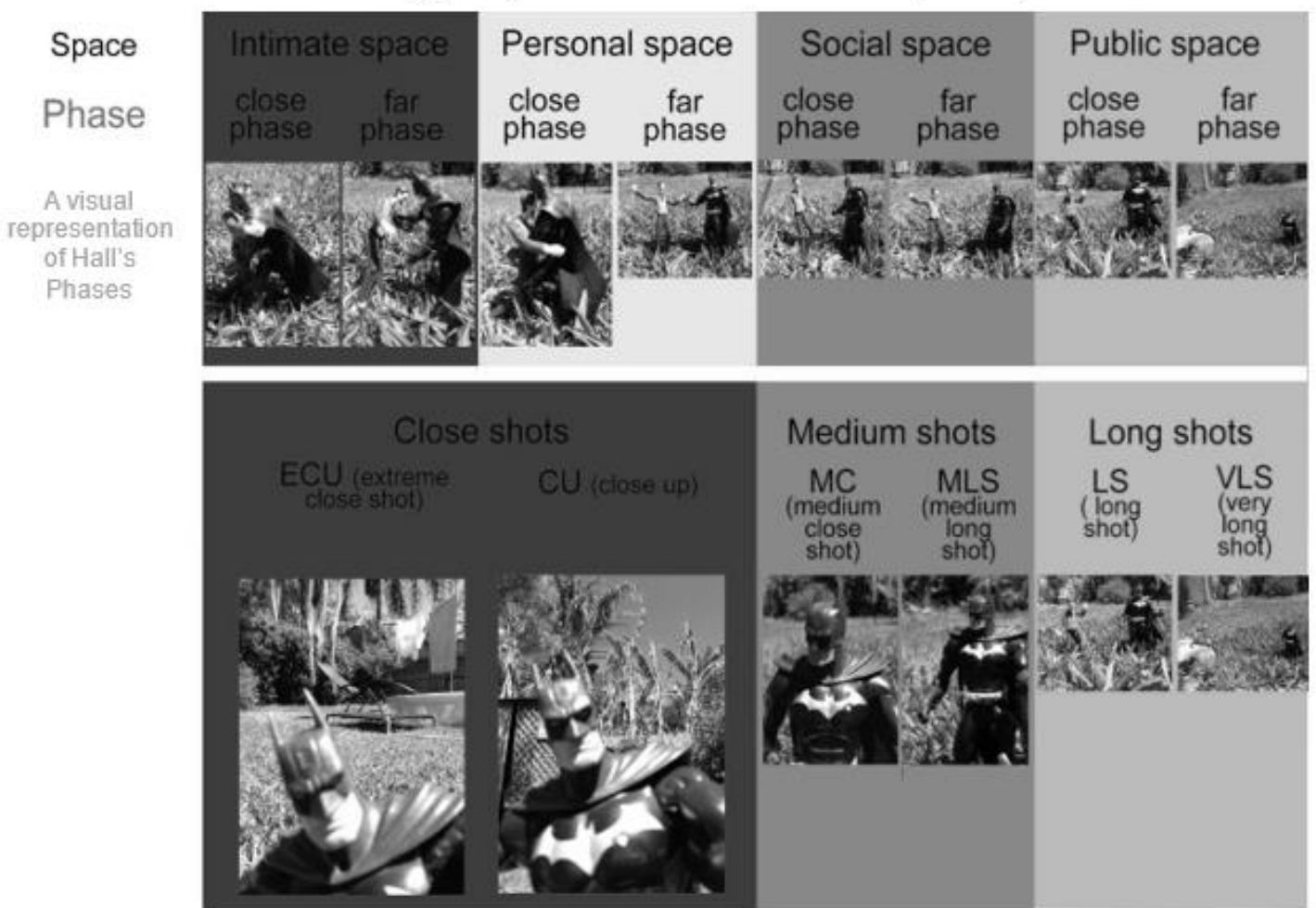

Table 2. Comparison table of visual representation of social distance relationships through photographic image performance (bottom row) and in everyday social interaction performance (top row). Image and table the produced and owned by the author

To visually locate proximity as it plays out between viewer and depicted in photographic social relationships I visually located selfies (table 2) in the shots Kress and Van Leeuwen have specified. Table 2 includes two rows of images. The top row of images are the same as those in table 1 that described Hall's proxemic spaces. The bottom row of images in the table are the shot types that Kress and Van Leeuwen have described in context of photography and film to understand visual relationship between the viewer of the image and the depicted. The columns of the images are aligned to suggest how Hall's theories of proxemics might be understood through photographic relationships of shot type and frame. For example, in the area of the first two columns and rows Intimate and personal space social relationships are gestured through the proxemics of close shots. Table 2 illustrates the relationships of the concept of proximity as gesture and the way it is framed in a selfie. The most typically understood and practiced selfies are those selfshot holding the mobile camera. The proxemic spaces these include can be the most intimate being the extreme close-up (ECU) where Batman's face is blurred a little. The personal space that can include or gesture a hug being the close-up (CU). The social space where the arm can extend out to the viewer and could include selfies with selfie sticks in the most extreme case indicated as medium long shots (MLS). Halls public 
space of proximity is not typically a proxemic relationship gestured in selfies, however people take selfies in public spaces and these could include images like the ECU of Batman where a background is included.

The most immediately obvious shift in the visual representation of the two rows is the point of view. The top row of the table that includes visual descriptions of Halls (1966) theory of proxemics in social relationships is illustrated between two characters that we view or look on at. The second row of visual descriptions of selfies that were created with reference to Kress and Van Leeuwen's (1996) professional camera shot types include the viewer as an active agent of the social proximity and interaction. Photographic practice is different to photographic or indeed visual depiction because the viewer and depicted are actively interacting directly, thus heightening the experience of intimate connection through the act.

The blurring of the performative spaces may lead to further misunderstanding between generational understandings of selfie gesture. The first two columns in table 1 include intimate and personal spaces of gestures in social relationships. However, in table 2 we observe that the comparison with the close shot includes both intimate and personal space that suggests an ambiguity in the gesture as a selfie that may be misconstrued by those not well educated in selfie practice. However, the limitation of the technology for selfies is most commonly limited by an outstretched arm or stick where the image will always remain gesturing more intimate social relationships.

When the close-up of the selfies gestures intimacy and it is performed and captured in a public setting, then in traditional contexts it could indeed cause controversy. Hall notes that intimate connection is a private matter most often socially acceptable in private space. However, selfies often include a mix of social spaces. Indeed, once a selfie is performed and shared, the producer no longer enjoys the agency of the performance and the image may make its ways into contexts and spaces beyond the authors original intent.

Traditionally the separation of private and public social spaces has been defined in photographic practice. The photobooth, for example, provided the capture of everyday images many years before the concept of selfies. Rettberg (2014) notes the experience of the photobooth including the private space inside where the image was captured separated by a curtain. The spaces were so close that in the private booth the noises and chatter of those lined up outside could be heard. The curtain in the scenario of the photobooth plays an important social role. It suggests that the performance of photography is a private matter and sections the space so that the performer can enjoy the privacy. In the selfie performance the curtain and booth are removed, and the performer exposed. 
Early studies of mobile media suggest that people enter a type of private bubble when consuming media. Bull (2005) for example explores music consumption through headphones where people might sing in public spaces or at least enter an invisible private bubble of consumption. People often experience this private bubble in their own cars where they perform as if they are in a private space singing or inspecting themselves in the mirror or other activities normally reserved for private spaces. Looking at one's own reflection is also something that is socially considered as limited to private spaces. However, the very performance of the selfie involves gazing at one's own mirrored image in public space and sharing this reflection. Selfie producers may experience this private bubble when taking selfies, however to those not familiar with the cultural experience it may appear to be crossing boundaries of socially defined spaces.

\section{Conclusion: Selfies as an evolution of visual intimacy and agency}

The selfie generation, and indeed all those who take and share selfies enjoy a transformation of visual cultural spaces. Understanding selfies as photographic performances that include the production and object in movement has provided a means through which to observe the ways the selfie gaze includes a transformation of the spaces of intimacy and agency.

\section{Intimacy}

The technology of photography as well as social relationships have evolved to be experienced intimately as an extension of the body. In the initial performative photographic spaces, the proximity is reduced to the extension of the arm. Through illustrations I have shown in this study how the proxemic distance between the body and camera have reduced in selfie performance. The space is more intimate because it is an extension of the body without interruption of a separate photographer nor a camera between the photographer and depicted. Rather the mobile phone acts as an extension of the body and an interaction between the photographer as depicted and self-viewed. This may be also immediately shared with others, rather than processed by other bodies and in other spaces. The immediacy of sharing also increases intimacy because the sharing brings people together at the very moment of experience. The mobility of the smartphone has been examined as an extension of the body for how it connects us with others (Farman, 2012) and how it is used as a decorative part of dress (Horst, 2016). In the act of sharing self-representations as selfies in the mirrored screens of smartphones the technology is an actual extension of our bodies that holds others close. Barthes (1981) described the intimacy experienced through the photographic image as an 
'umbilical cord' and its connectivity as a 'second skin'. Since Barthes wrote this, smart camera phone technology has enhanced the intimacy of photography in social interactions where it is not a second skin, but a limb of our everyday selves.

The selfie image signifies intimacy through the performance and through the closeness of the shot. Selfies are limited to the extension of the arm or a selfie stick producing images where the producer fills most of the frame. The close proximity in social relations falls within personal space (Hall, 1966) that signifies in the image greater intimacy between the viewer and depicted (Kress \& Van Leeuwen, 2006). Furthermore, within visual history dating back to modern painting the gaze in a mirror is socially represented as private and intimate space (Pollock, 1988). Here in the selfie the private space of mirrored reflection is captured uninterrupted.

\section{Agency of gaze}

The mirrored screen of mobile camera allows selfie producers to perform as depicted, viewer and photographer at once and this shifts the agency of the gaze. The mirror in the spaces of modern painting, such as Edouard Manet's (1965) 'Devant la glace'1 represent a subjective body where the active gaze is attributed to the viewer alone (Pollock, 1988). The depicted is subjected to a gaze and represented as inactive. In the painting 'Devant la glace' the woman peering at herself in the mirror is seen looking, but her face and gaze is not represented in the painting. The practice of self-representation selfies includes the depicted actively looking and producing. Through illustrations I have shown how the performance of traditional photography involved the depicted as subject to a gaze of the viewer and photographer. However, selfies provide a means through which the photographer is also the depicted and chooses how they are represented and shares that representation. In the first stage the photographer and depicted are also viewer in the mirrored screen, however as the image is shared (at the discretion of the selfie producer) there are also other viewers. The immediacy and ease of the technology means that the agency is in constant movement and the image may be shared or used in ways beyond the authors original intent. Despite this the agency of actively looking and producing the image in the first performance is important to the gesture of selfies and something not commonly available prior to mirrored screens.

The visual interactivity and intimacy experienced through selfies is indeed far greater than previous photographic performance, however the notions of selfies are also in

\footnotetext{
1 'Before the mirror' (1876, oil on canvas $(92.1 \times 71.4 \mathrm{~cm})$, Solomon R. Guggenheim Museum, New York, Thannhauser collection, gift, Justin K Thannhauser, 1978. https://www.guggenheim.org/artwork/2609
} 
constant movement through social contents. Understanding selfies means locating culturally how the mix and appropriation of social spaces of proximity are collaged to make meaning by individuals, as well as how these meaning change as they move through degrees of private and public spaces. The selfie gaze is interactive rather than simply active and is attributed with more agency (albeit in movement) then previously in History. Intimacy has also transformed through the performative social spaces of selfies. The proximity of selfies might suggest intimacy, but within a cultural context this is understood within aspects of the technological limits of the camera (distanced by the length of an arm) and social networks where contexts are in constant movement.

Future research extending form this study on visual social relationships such as selfies will involve looking more closely at visual beyond space or sight to more thoroughly investigate the kinesthetic and multisensory social interactions at play through new photographic practices.

\section{References}

Andreallo, F. (2017). The semeful sociability of digital memes; visual communication as active and interactive conversation. PhD thesis, University of Technology, Sydney. Retrieved from: https://opus.lib.uts.edu.au/handle/10453/120273

Barthes, R. (1981). Camera Lucida. Reflections on photography. New York: Hill and Wang.

Baym, N., \& Senft, T. (2015). What does the selfie say? Investigating the global phenomenon, International Journal of Communication, 9,1588-606.

Burgess, J. (2007). Vernacular creativity and New media PhD Thesis, Queensland University of Technology, Queensland, Australia.

Ehn, P., Binder, T., Eriksen, M. A., Jacucci, G., Kuutti, K., Linde, P., \& De Michelis, G. (2007). Opening the digital box for design work: supporting performative interactions, using inspirational materials and configuring of place (pp 50-76), in Streitz et al. (eds). The disappearing computer: interaction design, system infrastructures and applications for smart environments. Berlin/Heidelberg: Springer.

Farman, J. (2012). Mobile interface theory; embodied space and locative media. New York: Routledge.

Foucault, M. (1979). Discipline and punish; the birth of the prison ('Panopticism'). New York: Vintage.

Frosh, P. (2001). The public eye and the citizen-voyeur; Photography as a performance of power. Social semiotics, 11(1), 43-59.

Frosh, P. (2015). The gestural image: the selfie, photography theory, and kinesthetic sociability. International Journal of Communication, 9, 607-28. 
Fischer-Lichte, E. (2008a). Sense and sensation: exploring the interplay between the semiotic and performative dimensions of theatre. Journal of Dramatic Theory and Criticism, 22(2), 69-81.

Fischer-Lichte, E. (2008b). The transformative power of performance: a new aesthetics. London: Routledge.

Haggerty, K. (2006). Tear down the walls: On demolishing the panopticon, in Lyon (ed.). Theorising surveillance: The panopticon and beyond (pp. 23-45), Willan Press.

Hall, E. (1966). The hidden dimension. Garden City, New York: Doubleday.

Highfield, T., \& Leaver, T. (2016). Instagramatics \& digital methods; studying visual social media, from selfies and GIF to memes and emoji. Communication Research and Practice, 2(1), 47-62.

Kress, G., \& Van Leeuwen, T. (2001). Multimodal discourse: the modes and media of contemporary communication. New York: Oxford University Press.

Kress, G., \& Van Leeuwen, T. (2006 [1996]), Reading images. The grammar of visual design. New York: Routledge.

Mann, S. (2004). Sousveillance: Inverse Surveillance in Multimedia Imaging. In Proceedings of the 12th annual ACM international conference on Multimedia (pp. 620627). ACM.

Markham, A. (2009). How can qualitative researchers produce work that is meaningful across time, space and culture?, in Baym \& Markham (Eds.). Internet Inquiry, Conversations about Method (pp. 131-155). Thousand Oaks: Sage.

Metz, C. (1974). Film, Language; a semiotics of cinema, trans. New York: Oxford University Press.

Mulvey, L. (1981)., 'Afterthoughts. In Visual and other pleasures (pp. 29-38). Palgrave Macmillan, London.on 'Visual pleasure and Narrative cinema 'Inspired by King Vidor's Duel in the sun (1946)', Visual and other pleasures, pp. 29-38.

Mulvey, L. (1989). Visual pleasure and narrative cinema. In Visual and other pleasures (pp. 14-26). London: Palgrave Macmillan.

Mitchell, W.J.T. (1994). Picture theory. Chicago: University of Chicago Press.

Mitchell, W.J.T. (2013). Showing seeing: a critique of visual culture, in Mirzoeff (ed.). The visual culture reader (pp. 86-101), London/New York: Routledge.

Monahan, T. (Ed.). (2006). Surveillance and security: Technological politics and power in everyday life. Taylor \& Francis.

Pollock, G. (2018). Modernity and the Spaces of Femininity. In N. Broude \& M. Garrard (eds), The Expanding Discourse (pp. 244-267). London: Routledge.

Sekula, A. (1989). The body and the archive, in Bolton (ed.). The contest of meaning; critical histories of photography (pp. 342-88), Cambridge: MIT press.

Warfield, K. (2015) 'Why I love selfies and you should too (damn it)', paper presented to the Public lecture at Kwantlen Polytechnic University, 26 March 2014. Published on 
YouTube, 2 April 2014. Retrieved from: https://www.youtube.com/ watch?v=aOVIJwy3nVo.

Williamson J., Hansen, L. Jacussi, G., Light, L., \& Reeves, S. (2014). Understanding performative interactions in public settings. London: Springer verlag.

Zappavigna, M. (2016). Social media photography; construing subjectivity in instagram images. Visual communication, 15(3), 1-22.

Fiona Andreallo is a Lecturer in Digital Cultures in the Department of Media and Communications at the University of Sydney, Australia. Her transdisciplinary research focuses on the visual beyond sight to include multi-sensory experiences and a socio-cultural politics of visibility. The performance of gender and ideas of agency are central themes throughout her research. Her interdisciplinary approach is shaped by her industry background as a digital media artist and photographer employed in a variety of areas including medicine and advertising.

凶fiona.andreallo@sydney.edu.au 